\title{
Pain in young children attending an accident and emergency department
}

\author{
Clare McCarthy, Susie Hewitt, Imti Choonara
}

\begin{abstract}
Objectives-To assess pain in young children presenting to an accident and emergency $(\mathrm{A} \& \mathrm{E})$ department. To evaluate the use of the toddler-preschooler postoperative pain scale (TPPPS) and the use of analgesia in these children.

Methods-100 children aged 1-5 years presenting to an $A \& E$ department were assessed for pain. Pain assessments were carried out using a modified form of the TPPPS; a visual analogue scale by parents and a numerical scale by nursing staff.

Results-The majority of children were assessed as having pain: 60 by the TPPPS, 58 by the nurses and 63 by parents. Only 30 children, however, received analgesia. Children with the highest pain scores as assessed by nursing staff or using the TPPPS all received analgesia.

Conclusions-The pain scale appears suitable for use in young children in $A \& E$ departments. The subsequent management of pain in young children could be improved.

( $(\mathcal{A}$ Accid Emerg Med 2000;17:265-267)
\end{abstract}

Keywords: children; pain; pain assessment

There is an increased awareness regarding the assessment and management of pain in children. Most studies have concentrated on postoperative pain in children and comparatively few have considered the problems of pain in children presenting to accident and emergency (A\&E) departments. ${ }^{1-3}$ The assessment of pain is more difficult in young children and we wished to evaluate the use of a modified form of the toddler-preschooler postoperative pain scale (TPPPS) in young children aged $1-5$ years old. ${ }^{4}$ The TPPPS has been validated in 74 young children undergoing surgery, but has not been used in the $A \& E$ department before. ${ }^{4}$

\section{Methods}

All children aged $1-5$ years presenting to the A \& E Department at the Derbyshire Royal Infirmary or the Children's Emergency Department at Derbyshire Children's Hospital were considered suitable. Children with learning difficulties or life threatening conditions were excluded as the TPPPS was not designed for children with learning difficulties and it was felt unethical to approach parents for consent for children with life threatening conditions. The study was approved by the Southern Derbyshire Ethics Committee.

Pain assessments were carried out by the medical student (CM) at varying times of the day on different days to obtain different types of cases. Over a two month period, 100 children were entered into the study. A modified, simpler form of the TPPPS was used (table 1). If any of the eight parameters were present, this was noted and a cumulative score determined. The TPPPS scores could range from 0 to a maximum possible score of 8 . The higher the score, the greater the degree of pain. Parents were asked to assess their child's pain using a $10 \mathrm{~cm}$ visual analogue scale. They were asked to draw a line on the scale and this was then measured and rounded up to the nearest whole number giving a pain score out of 10 . Nursing staff were asked to score the child's pain at triage by choosing a number from number 1 to 10 where 10 represented the most severe pain and 0 represented no pain. Nursing staff were not informed of the TPPPS score. Spearman's rank correlation was used to correlate the TPPPS with the nurses' and parents' pain scales.

$2 \quad$ Cry - tears in the eyes or running down the face and/or making sobbing sounds.

Examples: sobbing, tears in the eyes, tears falling down cheeks.

Groan, moan, grunt - deep, low-pitched vocalisations expressing pain, hurt or discomfort.

Examples: non-intelligible, low-pitched sounds. May be drawn out (moan) or abrupt (grunt)

Scream - acute, loud, high pitched cry.

Examples: sharp, shrill, harsh, high-pitched vocalisation, shriek.

Facial expression of pain

Open mouth, lips pulled back at corners — open mouth, lips pulled back at corners with a downward pull on the jaw.

Squint/close eyes - eyelids taut, stiff, closed or nearly closed with wrinkling of the skin the lateral aspect of the eyes.

Brow bulge/forehead furrow - bulging, creasing, or furrows above and/or between the eyebrows.

Bodily expression of pain

Restless motor behaviour — rub/touch painful area, or unrestrained activity. May appear random or to lack goal direction. The body and/or

head is never still.

Examples: twisting and turning of torso and/or head while lying down, flailing of arms and/or legs, arching, repetitive fine motor activity. Child touches incisional area, iv site. 
Table 2 Presenting problems of 1-5 year olds and their associated pain scores

\begin{tabular}{lllll}
\hline Condition & $\begin{array}{l}\text { Number of } \\
\text { subjects }\end{array}$ & $\begin{array}{l}\text { Median } \\
\text { TPPPS } \\
\text { pain score }\end{array}$ & $\begin{array}{l}\text { Median } \\
\begin{array}{l}\text { nurses } \\
\text { pain score }\end{array}\end{array}$ & $\begin{array}{l}\text { Median } \\
\text { parents, } \\
\text { pain score }\end{array}$ \\
\hline Swollen penis & 1 & 4 & 5 & 7 \\
Pulled elbow & 4 & 3 & 4 & 6.5 \\
Fracture/suspected fracture & 8 & 2 & 2.5 & 5 \\
Burn & 2 & 1.5 & 3 & 5 \\
Laceration & 19 & 1 & 2 & 1 \\
Head injury with a laceration & 18 & 1 & 2 & 3 \\
Soft tissue injury & 14 & 1 & 3 & 5 \\
Dental problems & 5 & 1 & 1 & 5 \\
Infections & 10 & 1 & 0 & 0 \\
Foreign body & 6 & 0.5 & 0 & 0.5 \\
Head injury & 7 & 0 & 0 & 0 \\
Ingestion & 3 & 0 & 0 & 0 \\
Miscellaneous & 3 & 0 & 0 & 0 \\
\hline
\end{tabular}

\section{Results}

One hundred children were recruited into the study. No parent approached declined to take part in the study. Sixty six of the children were male and the median age of the children was 2 years. Twenty one patients were recruited from the Children's Emergency Department and 79 were recruited from the A \& E department.

Forty of the children were assessed as having no pain according to the TPPPS. The nurses' pain assessment suggested that 42 had no pain and parents estimated that 37 had no pain. The children had a variety of different clinical conditions (table 2). Children presenting to the emergency department were more likely to have medical conditions, such as infections and ingestions. These children had lower pain scores when assessed by the TPPPS or by nursing staff. Nine of the 21 children presenting to the emergency department were thought to be in pain and four of these received analgesia. Fifty one of the 79 children presenting to the $A \& E$ department were felt to be in pain and 26 of these received analgesia.

The median TPPPS score was 1 with a range of $0-5$. The nurses' median pain score was 2 , range $0-8$. The parent's median pain score was also 2 , range $0-10$. Of the 60 children who had a TPPPS score of 1 or more, 30 received no analgesia either at home or in hospital. Ten

Table 3. Number of children in each TPPPS score category and how many received analgesia

\begin{tabular}{lllllll}
\hline $\begin{array}{l}\text { TPPPS } \\
\text { score }\end{array}$ & $\begin{array}{l}\text { Number of } \\
\text { subjects }\end{array}$ & $\begin{array}{l}\text { Received no } \\
\text { analgesia }\end{array}$ & $\begin{array}{l}\text { Received } \\
\text { paracetamol } \\
\text { from parents }\end{array}$ & $\begin{array}{l}\text { Received } \\
\text { paracetamol } \\
\text { from nurse }\end{array}$ & $\begin{array}{l}\text { Received } \\
\text { ibuprofen } \\
\text { from nurse }\end{array}$ & $\begin{array}{l}\text { Received } \\
\text { oral } \\
\text { morphine }\end{array}$ \\
\hline 1 & 30 & 17 & 6 & 7 & 0 & 0 \\
2 & 16 & 8 & 3 & 5 & 1 & 0 \\
3 & 11 & 5 & 0 & 6 & 0 & 0 \\
4 & 2 & 0 & 0 & 0 & 0 & 2 \\
5 & 1 & 0 & 1 & 0 & 1 & 1 \\
\hline
\end{tabular}

Table 4 Number of children in each score category according to the nurses'pain score and how many received analgesia

\begin{tabular}{lccllll}
\hline $\begin{array}{l}\text { Nurses } \\
\text { pain score }\end{array}$ & $\begin{array}{l}\text { Number of } \\
\text { subjects }\end{array}$ & $\begin{array}{l}\text { Received no } \\
\text { analgesia }\end{array}$ & $\begin{array}{l}\text { Received } \\
\text { paracetamol } \\
\text { from parents }\end{array}$ & $\begin{array}{l}\text { Received } \\
\text { paracetamol } \\
\text { from nurse }\end{array}$ & $\begin{array}{l}\text { Received } \\
\text { ibuprofen } \\
\text { from nurse }\end{array}$ & $\begin{array}{l}\text { Received } \\
\text { oral } \\
\text { morphine }\end{array}$ \\
\hline 1 & 7 & 4 & 3 & 1 & 0 & 0 \\
2 & 17 & 14 & 2 & 1 & 0 & 0 \\
3 & 8 & 2 & 1 & 5 & 0 & 0 \\
4 & 9 & 4 & 2 & 3 & 0 & 0 \\
5 & 13 & 5 & 1 & 6 & 1 & 1 \\
6 & 1 & 0 & 0 & 1 & 0 & 0 \\
7 & 2 & 0 & 0 & 2 & 1 & 1 \\
8 & 1 & 0 & 0 & 0 & 0 & 1 \\
\hline
\end{tabular}

children received paracetamol from their parents before arrival at the emergency department. Twenty one children received analgesia in the emergency department (one child received analgesia both at home and in the emergency department). Paracetamol was the most widely used analgesic (28 children). Three children received oral morphine, one of whom also received ibuprofen. One child received paracetamol and ibuprofen. The three children with TPPPS scores of 4 or more all received analgesia including morphine. The analgesia received in relation to the TPPPS score is shown in table 3.

Table 4 shows the analgesia received in relation to the nurses' assessment of the child's pain. Children with pain scores of 6 or more all received analgesia. It is of concern that five of the children who had a pain score of 5 received no analgesia either from the parents or nursing staff. The TPPPS scores were significantly correlated with the nurses' pain scores (Spearman's rank correlation 0.78). The TPPPS was also significantly correlated with the parents' pain scores (Spearman's rank correlation $0.77)$.

\section{Discussion}

The majority of children presenting to emergency departments in Derby had pain using assessments by parents, nurses and the modified TPPPS score by a medical student. Approximately half of these children in pain received no analgesia either from parents or health professionals. The importance of pain in children in such departments has been highlighted by both individuals and a recent report on $(A \& E)$ services for children issued by the Royal College of Paediatrics and Child Health..$^{56}$ This report recommends that pain assessment be carried out at triage. ${ }^{6}$ This is important but needs to be accompanied by the more frequent use of analgesia such as paracetamol in children presenting with painful conditions. Others have shown that children are less likely to receive analgesia than adults in the A\&E setting and that young children are less likely to receive analgesia than older children. $^{7}$ Unfortunately, we were unable to reassess pain scores after the administration of analgesia. Further studies are required to evaluate the efficacy of interventions.

The management of pain is dependent on its accurate assessment. This is more difficult in young children. The modified TPPPS that we used was found to be suitable for the assessment of pain in children. A pre-clinical medical student found the TPPPS easy to use and the assessment took no more than a few minutes to perform. The pain scale scores correlated with the scores given by the nurses and the parents. It is clear that this pain scale is of value in other clinical situations as well as postoperatively. We therefore propose that this modified form be known as the toddlerpreschooler pain scale (TPPS) and that its use be evaluated by others both within the emergency department and possibly in other clinical areas. 
Contributor

Clare McCarthy both designed and carried out the study. She was also involved in the analysis and writing of the paper. Susie Hewitt was involved in the design of the study, analysis of the data and writing of the paper. Imti Choonara initiated the research, helped design the study and was involved in analysis and writing of the paper. $\mathrm{He}$ is also the guarantor of the paper. Funding: none.

Conflicts of interest: IC is in receipt of research grants from Astra and Chiroscience in relation to the managment of pain.

1 Selbst SM. Managing pain in the pediatric emergency department. Pediatr Emerg Care 1989;5:56-63.

2 Jylli L, Olsson GL. Procedural pain in a paediatric surgical emergency unit. Acta Paediatr 1995;84:1403-8.
3 Petrack EM, Christopher NC, Kriwinsky J. Pain managePetrack EM, Christopher NC, Kriwinsky J. Pain manage-
ment in the emergency department: patterns of analgesic ment in the emergency department:
utilisation. Pediatrics 1997;99:711-14.

4 Tarbell SE, Cohen IT, Marsh JL. The Toddler-Preschooler Postoperative Pain Scale: an observational scale for measuring post-operative pain in children aged 1-5. Preliminary report. Pain 1992;50:273-80.

5 Simpson N, Finlay F. Only one fifth of A\&E departments were found to have pain control policy for children. $B M F$ 1998;316:396.

6 Accident and Emergency Services for Children. Report of a Multidisciplinary Working Party. London: Royal College of Paediatrics and Child Health, 1999.

7 Selbst SM, Clark M. Analgesic use in the emergency department. Ann Emerg Med 1990;19:1010-13. 